\title{
Visual evoked potentials and selective attention to points in space
}

\author{
STEVEN VAN VOORHIS and STEVEN A. HILLYARD \\ Department of Neurosciences, University of California, San Diego, La Jolla, California 92093
}

\begin{abstract}
Visual evoked potentials (VEPs) were recorded to sequences of flashes delivered to the right and left visual fields while subjects responded promptly to designated stimuli in one field at a time (focused attention), in both fields at once (divided attention), or to neither field (passive). Three stimulus schedules were used: the first was a replication of a previous study (Eason, Harter, \& White, 1969) where left- and right-field flashes were delivered quasi-independently, while in the other two the flashes were delivered to the two fields in random order (Bernoulli sequence). VEPs to attended-field stimuli were enhanced at both occipital $\left(\mathrm{O}_{2}\right)$ and central $\left(\mathrm{C}_{\mathrm{z}}\right)$ recording sites under all stimulus sequences, but different components were affected at the two scalp sites. It was suggested that the VEP at $\mathrm{O}_{2}$ may reflect modality-specific processing events, while the response at $\mathrm{C}_{\mathrm{z}}$, like its auditory homologue, may index more general aspects of selective attention.
\end{abstract}

The neural systems which mediate selective visual attention in man have been studied extensively by recording the visual evoked potentials (VEPs) from the scalp while a subject shifts his attention between different classes of photic stimuli (for recent reviews, see Hillyard \& Picton, in press; Näätänen, 1975). In order to certify that a component of the VEP is a physiological correlate of selective visual processing, however, several stringent methodological criteria must be met. First, the evoked component must be preferentially associated with the "attended" stimulus class and then "switch over" to the other class when attention is shifted to those previously irrelevant stimuli. Second, the relevant and irrelevant stimuli must be delivered in a random temporal sequence to prevent the subject from anticipating which stimulus will occur next and adjusting his prior level of arousal or alertness (Karlin, 1970; Näätänen, 1967). Thirdly, the visual stimulus at the receptors must be held invariant across experimental conditions by monitoring the subject's direction of gaze, state of accommodation, and/or pupil size, whenever appropriate. Fourthly, the trials on which eyeblinks, eye movements, or other muscle artifacts occur must be rejected or compensated in the data analysis to prevent contamination of the VEP. Finally, it is desirable to obtain behavioral measures of stimulus detectability or discriminability concurrently with the VEPs, so that physiological and psychological indices of selective processing can be compared. The majority of the earlier studies reporting changes in the VEP as a function of attention have been

This work was supported by NIH Grant MH 25594-03 to S.A. Hillyard and NASA Grant NGR 05-009198-04 to R. Galambos. criticized for failure to control one or more of these factors (Hillyard \& Picton, in press; Karlin, 1970; Näätänen, 1975).

A number of adequately controlled studies have established that a late positive wave (the " $\mathrm{P}_{3}$ " or " $P_{300}$ " component) is differentially emitted following task-relevant visual stimuli, after a latency of 300-400 msec (Chapman, 1973; Courchesne, Hillyard, \& Galambos, 1975; Donchin \& Cohen, 1967; Harter \& Salmon, 1972; Rohrbaugh, Donchin, \& Eriksen, 1974; Ruchkin \& Sutton, 1973). This $\mathrm{P}_{300}$ wave is widely considered to be a modality nonspecific brain event which follows the selection of a relevant stimulus rather than a unique index of selective visual processing (Ritter, Simson, \& Vaughan, 1972; Simson, Vaughan, \& Ritter, 1976; N. Squires, Donchin, K. Squires, \& Grossberg, in press). There has been little reliable evidence, however, that paying attention selectively can modify evoked visual activity prior to $200 \mathrm{msec}$ (Hartley, 1970; Hillyard \& Picton, in press). This is in marked contrast to the auditory modality, in which substantial increases of the evoked $N_{1}$ component beginning at $70-90 \mathrm{msec}$ have been related to selective listening to tones or speech messages (Hillyard, Hink, Schwent, \& Picton, 1973; Hink \& Hillyard, 1976; Schwent \& Hillyard, 1975; Schwent, Hillyard, \& Galambos, 1976a, 1976b; Schwent, Snyder, \& Hillyard, 1976c).

Eason, Harter, and White (1969) have reported a clear and consistent enhancement of relatively early components of the VEP to flashes at an attended locus in space, with a negative peak at $160-180 \mathrm{msec}$ showing the most dramatic changes. In their study, $1^{\circ}$ flashes were presented irregularly to the right or left of the fixation point while subjects attended and responded to those on one side at a time. 
Näätänen (1975) has noted, however, that the rightand left-field flashes did not occur in a completely random, unpredictable sequence, and he suggested that the enhancement of the VEP to the attended flashes may have resulted from a differential anticipatory state rather than from selective processing. Moreover, Eason et al. (1969) did not take an objective measure of the subject's eye position to guard against his looking from the fixation point towards the attended flashes.

Since the changes in the occipital VEP reported by Eason et al. (1969) appeared to be strong and reliable, and were in certain respects analogous to the attention effects reported for the auditory $\mathrm{N}_{1}$ component, we decided to replicate their study while controlling for visual fixation and for the degree of randomness in the stimulus sequences. In one condition of the present study, right and left field flashes were delivered according to schedules that were largely independent of one another (the same as Eason et al., 1969). In a second condition, right and left flashes were delivered in a completely random (Bernoulli) sequence at the same overall mean rate $(0.4 / \mathrm{sec})$. If Näätänen's (1975) hypothesis is correct, this randomization of the stimulus order should eliminate the "attention effects" on the VEP. In a third condition, flashes were again presented in a bernoulli sequence, but at a much faster mean rate $(2.2 / \mathrm{sec})$, to investigate whether a higher information load might increase the selectivity of processing (Schwent et al., 1976a). To enable further comparisons between the present study and the auditory work on selective attention, VEPs were recorded from vertex as well as the occipital site, and a condition of divided attention (to both fields at once) was included to relate VEP amplitudes to the subject's allocation of his attentional capacity (Hink, Van Voorhis, Hillyard, \& Smith, in press).

\section{METHOD}

\section{Subjects}

The subjects were 12 young adults, 6 male and 6 female, who were paid for participating in the experiment.

\section{Stimulii}

The stimulus arrangement consisted of a translucent white screen with a luminance of $0.64 \mathrm{~cd} / \mathrm{m}^{2}$, measuring $35 \times 43 \mathrm{~cm}$, and positioned $40 \mathrm{~cm}$ from the subject's eyes. In the center of the screen was a $1^{\circ}$ black dot designated as the fixation point. Circular flashes subtending $1^{\circ}$ of visual angle were presented through the translucent screen from two Grass photo stimulators, positioned $20^{\circ}$ to the left and right of the fixation point, respectively. All flashes were presented at a luminance of one log unit above the subject's threshold. The subjects viewed the stimuli binocularly and wore earphones which delivered continuous white noise at $60 \mathrm{~dB}$ SL to mask extraneous sounds and photostimulator discharge.

\section{Design}

Stimuli were presented according to three different schedules which were generated by a PDP-11/45 computer and recorded on audio tape.

In the first schedule (a replication of Eason et al., 1969), the right and left field flashes were presented in accordance with two independent, concurrently running sequences. Each sequence delivered flashes at random intervals between 2 and $8 \mathrm{sec}$ (rectangular distribution), with the additional proviso that the minimum cross-channel interstimulus interval (ISI) was $1.0 \mathrm{sec}$. In the second schedule (slow, random), left and right flashes occurred in random order with equal probability following a single bernoulli distribution, with ISIs ranging from 1.0 to $4.0 \mathrm{sec}$ (rectangular distribution). The third schedule (fast random) also consisted of a bernoulli sequence of equiprobable left and right field flashes, but the ISIs ranged from 300 to $600 \mathrm{msec}$ (rectangular distribution). In addition, 10\% of these flashes were "targets" (doublets separated by $70 \mathrm{msec}$ ) randomly distributed throughout the sequence, to which the subjects were required to respond in some conditions.

For each of the three stimulus schedules, the subjects were required to perform under four conditions of attention: passive, attend-left field, attend-right field, and attend-both fields. In the passive condition, the subjects were told to fixate the black dots and make no overt behavioral responses. In the three activeattention conditions using the replication and slow random schedules, the subject responded to each flash in the attended visual field(s) by pressing a button as fast as possible with the right thumb. In the three active-attention conditions with the fast random schedule, however, he pressed the button only after detecting a doublet flash (target) in the appropriate visual field(s).

Each subject was run in two sessions, 1 week apart. The second session was a complete replication of the first, with the experimental conditions administered in reverse order. In each session, the subjects were run through all 12 experimental conditions (three stimulus sequences by four attention conditions). One block of 150 total stimuli was given for the replication and slow random schedules in each attention condition, while two blocks of the fast random schedule (a total of 300 stimuli) were given under each attention condition. The order of presentation of attention conditions and stimulus schedules was counterbalanced across subjects.

\section{Procedure}

At the start of each session, the subject's threshold was determined for the stimuli in each visual field by the method of descending limits, using interposed neutral density filters. A short practice session was given under each experimental condition to ensure that the subject could properly identify the appropriate stimuli. He was not told of the difference between the slow random and replication schedules.

Recording electrodes were placed at $\mathrm{C}_{\mathrm{z}}$ and $\mathrm{O}_{2}$ sites (International 10-20 system) and below the right eye, all referenced to the right mastoid. The left mastoid was grounded. These channels were amplified with Grass 7P5 preamplifiers (bandpass 0.15 to $500 \mathrm{~Hz}$ ). In addition, horizontal eye position was monitored via a bipolar dc recording of the electrooculogram (EOG) between the left and right lateral canthi using Beckman silver/silverchloride electrodes and a Grass 7P1 preamplifier with polygraph writeout. In order to minimize dc drift in these recordings, the electrodes were stored in conductive media with the ends shorted together, and the interelectrode impedance during the recording was maintained below $5 \mathrm{~K}$ ohms. This method measures shifts in eye position with a resolution of better than $2^{\circ}$ (Trevarthan \& Tursky, 1969). ${ }^{1}$

Before the start of each block of trials, the subject was instructed to fixate successively the black dot, left stimulus location, right stimulus location, and black dot again in order to calibrate the dc horizontal eye position channel. Then, while he was fixating the central dot, the subject was told which visual field (left, right, both, or neither) would be attended in the upcoming block. He was reminded to keep the black dot fixated and to avoid blinking. 
The block was then begun. Failure of the subject to fixate the black dot resulted in halting the experiment and restarting that block from the beginning. In this way, it was not possible for the subject to bias his fixation systematically towards the attended stimulus location.

\section{Data Analysis}

Coded stimulus triggers, reaction time (RT) markers, EEG, and eye-movement channels were tape-recorded (Vetter FM-5, bandpass $0-300 \mathrm{~Hz}$ ) for off-line analysis, using a Nicolet 1072 signal averager. Trials containing eye blinks or phasic eye movements were marked and excluded from further analysis. For each of the two sessions, VEPs were averaged separately for right- and leftfield flashes, over 64 stimuli for the replication and slow random schedules and over 128 of the nontarget stimuli for the fast random schedule, under each of the four attention conditions. Peak amplitudes of the different components were measured with reference to a $50-\mathrm{msec}$ prestimulus baseline according to the following criteria: $P_{1}$ was defined as the largest positive deflection between 65 and $140 \mathrm{msec}$ poststimulus, $N_{1}$ as the most negative deflection between $120-200 \mathrm{msec}, \mathrm{P}_{2}$ as the most positive deflection between $180-240 \mathrm{msec}$, and $P_{3}$ as the most positive deflection between 320 and $500 \mathrm{msec}$.

For the replication and slow random schedules, the median of the RT distribution for each condition was determined. For the fast random schedule, buttonpresses made within a 2001,000-msec posttarget window were considered as hits, and all other responses as false alarms. The obtained hit and false-alarm probabilities were used to calculate the signal detection parameters $d^{\prime}$ and $\beta .^{2}$

Since there were no significant differences in any of the VEP measures between sessions, the data was collapsed over both sessions for purposes of quantitative analysis. Unless otherwise noted, statistical comparisons were done by repeated measures analyses of variance.

\section{RESULTS}

\section{Evoked Potentials}

Typical VEP waveforms are illustrated in Figure 1, which shows the responses of one subject to rightand left-field flashes presented at the two slower rates (replication and slow random schedules). The major components, $P_{1}, N_{1}, P_{2}$, and $P_{3}$, were observed at both $\mathrm{C}_{2}$ and $\mathrm{O}_{2}$ electrode sites in nearly every subject and condition. As is evident in Figure 1, some components did not always occur at exactly the same latency at the $\mathrm{C}_{2}$ and $\mathrm{O}_{2}$ electrodes. Both the $\mathrm{P}_{1}$ and $N_{1}$ waves peaked significantly later (see Table 1) at the $\mathrm{O}_{2}$ site than at $\mathrm{C}_{\mathrm{z}}(\mathrm{p}<.01$ for both waves), suggesting that these waves may reflect contributions from separate neural generators at the two sites. The $\mathrm{P}_{2}$ and $\mathrm{P}_{3}$ waves, however, could not be so subdivided on the basis of latency evidence. In several subjects, there was an asymmetry between the VEP amplitudes to ipsilateral (right field) and contralateral (left field) flashes at the $\mathrm{O}_{2}$ site (Figure 1), but it failed to reach overall statistical significance.

Attention effects. The direction of attention had significant differential effects upon the amplitudes of VEPs to left- and right-field stimuli for all three stimulus sequences (Figures 1 and 2). Since the effects of attention did not differ significantly for right- and left-field flashes, the VEP amplitudes in
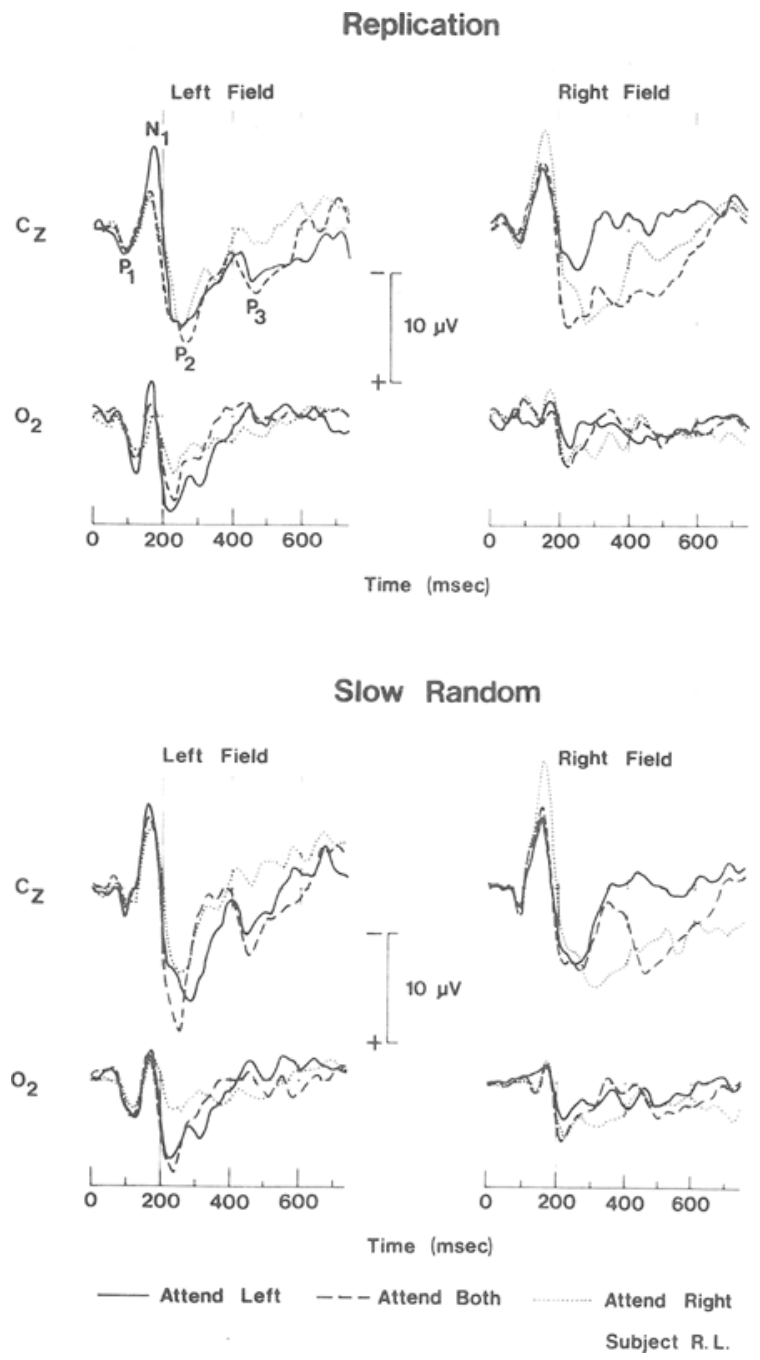

Figure 1. Vertex and occipital responses from one subject evoked by left and right field flashes under three conditions of attention for both the replication and slow random schedules. Each tracing is an average of 128 responses.

Table 2 are averaged across both fields (e.g., to obtain the "focused-attended" amplitudes, the leftfield response during the attend-left condition was averaged with the right-field response during the attend-right condition, etc). In general, VEPs were largest to flashes in a given field when they received unilateral or focused attention, smallest when attention was focused on the opposite field, and intermediate in amplitude when attention was divided between both fields (Table 2). These effects of attention were most prominent and consistent for the $\mathrm{N}_{1}$ component at $\mathrm{C}_{\mathrm{z}}$, and for the $\mathrm{P}_{1}$ and $\mathrm{P}_{2}$ components at $\mathrm{O}_{2}$. The $P_{3}$ wave was also greatly enlarged at both electrode sites to attended-field flashes.

The percentages by which the various VEP components were incremented by shifting attention between the fields are shown in Table $3 .^{3}$ At the 
Fast Random

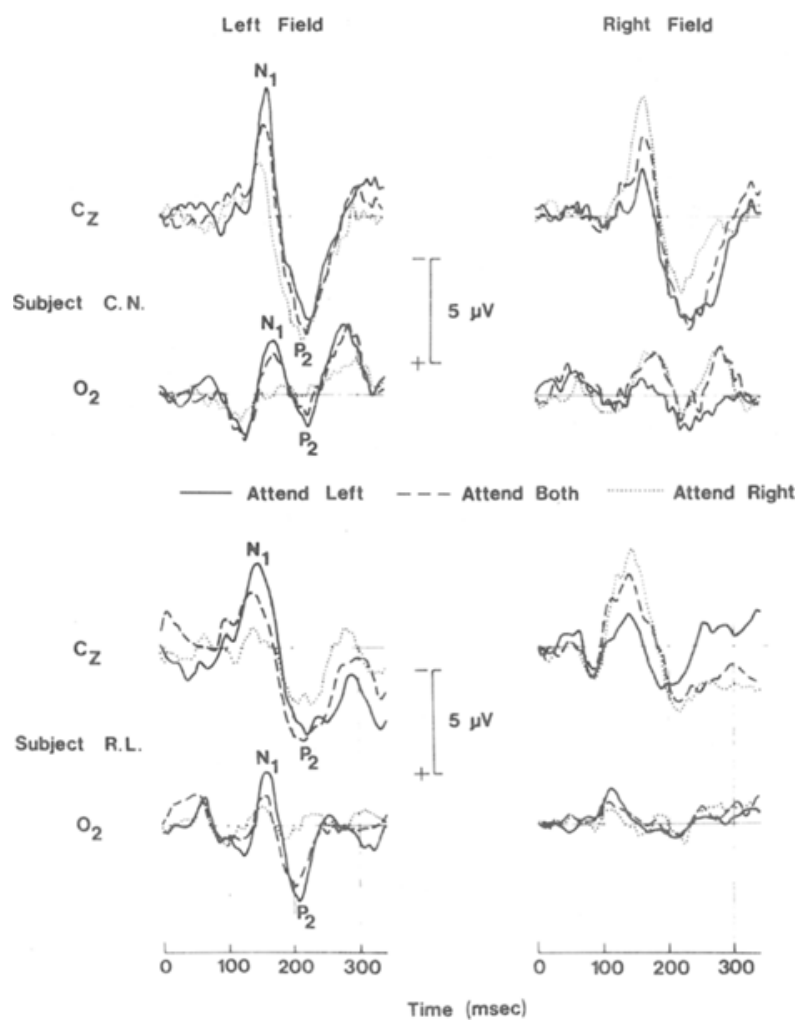

Figure 2. Vertex and occipital responses evoked by left and right field flashes under three conditions of attention for the fast random schedule. Each tracing is an average of 256 responses. Two subjects.

vertex, the $N_{1}$ wave and, less consistently, the $P_{1}$ wave were enhanced to attended-field stimuli under all schedules, making the $P_{1}-N_{1}$ measure the strongest electrophysiological sign of selective attention. Although the effect of attention on $P_{1}-N_{1}$ and on most other components was largest with the fast random schedule, there were no statistically significant differences among the three schedules in the magnitude of attention effects at $C_{z}$.

A more detailed picture of the changes in the vertex-recorded $P_{1}-N_{1}$ as a function of attention is shown in Figure 3. Note the reciprocal and symmetrical amplitude changes as attention was shifted between the two visual fields, an effect seen in $12 / 12$
Replication

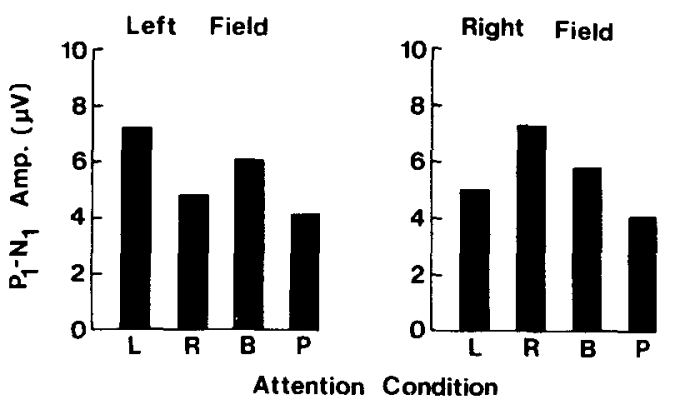

Slow Random

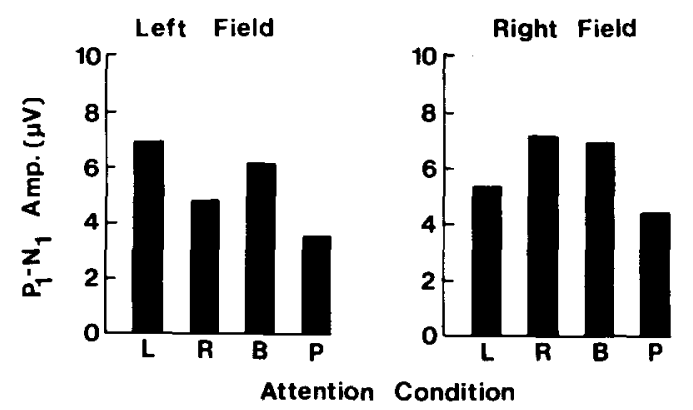

Fast Random

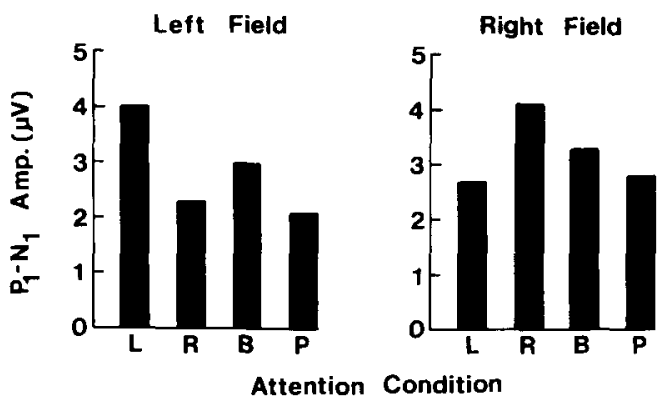

Figure 3. Mean amplitudes of the $P_{1}-N_{1}$ measure at the vertex across all subjects under the three different stimulus schedules and four attention conditions $(L=$ attend left, $R=$ attend right, $\mathrm{B}=$ attend both, $\mathbf{P}=$ passive $)$.

Table 1

Component Latencies (Mean \pm Standard Error)

\begin{tabular}{|c|c|c|c|c|c|c|c|c|}
\hline & \multicolumn{4}{|c|}{$\mathrm{C}_{\mathrm{z}}$} & \multicolumn{4}{|c|}{$\mathrm{O}_{2}$} \\
\hline & $\mathrm{P}_{1}$ & $\mathrm{~N}_{1}$ & $\mathrm{P}_{2}$ & $\mathrm{P}_{3}$ & $P_{1}$ & $\mathrm{~N}_{1}$ & $\mathrm{P}_{2}$ & $\mathrm{P}_{3}$ \\
\hline $\begin{array}{l}\text { Replication } \\
\text { Slow Random } \\
\text { Fast Random }\end{array}$ & $\begin{array}{l}96 \pm 3 \\
95 \pm 3 \\
93 \pm 3\end{array}$ & $\begin{array}{l}157 \pm 3 \\
159 \pm 4 \\
150 \pm 3\end{array}$ & $\begin{array}{l}219 \pm 4 \\
221 \pm 5 \\
214 \pm 3\end{array}$ & $\begin{array}{l}396 \pm 7 \\
393 \pm 8\end{array}$ & $\begin{array}{l}104 \pm 4 \\
105 \pm 4 \\
107 \pm 4\end{array}$ & $\begin{array}{l}164 \pm 4 \\
168 \pm 3 \\
168 \pm 4\end{array}$ & $\begin{array}{l}222 \pm 4 \\
223 \pm 4 \\
221 \pm 3\end{array}$ & $\begin{array}{l}388 \pm 6 \\
381 \pm 6\end{array}$ \\
\hline Mean & 95 & 155 & 218 & 395 & 105 & 167 & 222 & 385 \\
\hline
\end{tabular}


Table 2

Mean Amplitudes $(\mu \mathrm{V})$ of VEP Components From All Experimental Conditions, Averaged Across Right and Left Visual Fields

\begin{tabular}{|c|c|c|c|c|c|c|c|c|c|c|c|c|}
\hline & \multicolumn{6}{|c|}{$\mathrm{C}_{\mathrm{z}}$} & \multicolumn{6}{|c|}{$\mathrm{O}_{2}$} \\
\hline & $\mathrm{P}_{1}$ & $\mathbf{N}_{1}$ & $\mathbf{P}_{2}$ & $P_{1}-N_{1}$ & $\mathrm{~N}_{1}-\mathrm{P}_{2}$ & $\mathbf{P}_{3}$ & $P_{1}$ & $\mathrm{~N}_{1}$ & $\mathbf{P}_{2}$ & $P_{1}-N_{1}$ & $N_{1}-P_{2}$ & $\mathrm{P}_{3}$ \\
\hline \multicolumn{13}{|l|}{ Replication } \\
\hline Focused-Attended & 1.8 & 5.4 & 4.6 & 7.2 & 10.0 & 5.8 & 2.1 & 1.9 & 3.7 & 4.0 & 5.6 & 3.9 \\
\hline Divided Attention & 1.5 & 4.4 & 5.0 & 5.9 & 9.4 & 5.7 & 1.8 & 1.5 & 4.2 & 3.4 & 5.7 & 2.7 \\
\hline Focused-Unattended & 1.0 & 3.8 & 4.2 & 4.8 & 8.0 & 2.3 & 1.0 & 1.9 & 1.5 & 2.9 & 3.4 & 1.6 \\
\hline Passive & 1.3 & 2.8 & 4.5 & 4.1 & 7.3 & 1.6 & 1.3 & 1.6 & 1.8 & 2.9 & 3.4 & 1.7 \\
\hline \multicolumn{13}{|l|}{ Slow Random } \\
\hline Focused-Attended & 1.7 & 5.3 & 4.4 & 7.0 & 9.7 & 6.5 & 1.6 & 2.0 & 3.4 & 3.6 & 5.4 & 4.3 \\
\hline Divided Attention & 1.9 & 4.5 & 4.8 & 6.4 & 9.3 & 6.5 & 1.8 & 2.4 & 4.1 & 4.2 & 6.5 & 3.1 \\
\hline Focused-Unattended & 1.3 & 3.7 & 3.7 & 5.0 & 7.4 & 2.1 & 1.0 & 2.0 & 1.8 & 3.0 & 3.8 & 1.6 \\
\hline Passive & 1.2 & 2.7 & 4.7 & 3.9 & 7.4 & 2.8 & 1.2 & 1.6 & 2.0 & 2.8 & 3.6 & 1.6 \\
\hline \multicolumn{13}{|l|}{ Fast Random } \\
\hline Focused-Attended & 1.3 & 2.8 & 3.3 & 4.1 & 6.1 & & 1.2 & 1.9 & 1.8 & 3.1 & 3.7 & \\
\hline Divided Attention & .6 & 2.5 & 2.9 & 3.1 & 5.4 & & 1.1 & 1.8 & 1.6 & 2.9 & 3.4 & \\
\hline Focused-Unattended & .7 & 1.7 & 2.4 & 2.4 & 4.1 & & .8 & 1.3 & 1.1 & 2.1 & 2.4 & \\
\hline Passive & .7 & 1.7 & 2.3 & 2.4 & 4.0 & & .9 & 1.3 & 1.2 & 2.2 & 2.5 & \\
\hline
\end{tabular}

Table 3

Percentage Increments of VEP Components, Comparing Attended vs. Unattended Visual Field

\begin{tabular}{|c|c|c|c|c|c|c|c|c|c|c|c|c|}
\hline & \multicolumn{6}{|c|}{$\mathrm{C}_{\mathrm{z}}$} & \multicolumn{6}{|c|}{$\mathrm{O}_{2}$} \\
\hline & $P_{1}$ & $\mathrm{~N}_{1}$ & $\mathrm{P}_{2}$ & $P_{1}-N_{1}$ & $\mathrm{~N}_{1}-\mathrm{P}_{2}$ & $P_{3}$ & $\mathrm{P}_{1}$ & $\mathbf{N}_{1}$ & $\mathrm{P}_{2}$ & $P_{1}-N_{1}$ & $\mathrm{~N}_{1}-\mathrm{P}_{2}$ & $\mathrm{P}_{3}$ \\
\hline Replication & 80 & $42 *$ & 10 & $50+$ & $25^{* *}$ & $152 \dagger$ & $110 \dagger$ & 0 & $146 \dagger$ & $38 *$ & $65^{* *}$ & $144 \dagger$ \\
\hline Slow Random & 31 & $43^{*}$ & 19 & $40 * *$ & $31 * *$ & $210 \dagger$ & 60 & 0 & $89 *$ & 20 & 42 & $169 \dagger$ \\
\hline Fast Random & 43 & $65^{*}$ & $38 * *$ & $71 \dagger$ & $49 \dagger$ & & 50 & $46^{*}$ & $64 *$ & $48 \dagger$ & $54 * *$ & \\
\hline
\end{tabular}

Note-One-tailed t test on $\mu V$ differences; significance levels $=* .025,{ }^{* *} .01,+.001$.

subjects with the replication, in $10 / 12$ with the slow random and in 11/12 with the fast random schedule. The mean $P_{1}-N_{1}$ averaged across both fields during divided attention was intermediate in amplitude between those evoked by attended and unattended flashes during focused attention. The amplitude of $P_{1}-N_{1}$ in the passive condition was typically about the same as that elicited by stimuli in the unattended field.

At the $\mathrm{O}_{2}$ site, however, the $\mathrm{N}_{1}$ was the component least sensitive to shifts in the direction of attention, while $P_{1}$ and $P_{2}$ were more consistently enhanced with attention under all schedules. The $P_{1}$ showed significantly greater attention-related enhancement under the replication schedule as compared with both the slow random $(p<.05)$ and fast random $(p<.01)$ schedules. The $P_{2}$ demonstrated significantly less additional enhancement under the fast random as compared with either of the two slower schedules (vs. replication, $\mathrm{p}<.01$; vs. slow random, $\mathrm{p}<.05$ ). This is in contrast to the situation at $\mathrm{C}_{\mathrm{z}}$, where the largest effects of attention were generally observed under the fast random schedule.

Further dissociations were observed between the effects of attention on $\mathrm{C}_{z}$ and $\mathrm{O}_{2}$ components. An example is shown in Figure 2 (subject R.L.); paying attention to left-field flashes increased $N_{1}-P_{2}$ to those stimuli at both $\mathrm{C}_{\mathrm{z}}$ and $\mathrm{O}_{2}$ sites, whereas attending to the opposite field markedly enhanced $N_{1}$ at the vertex to right-field flashes without any augmentation of the $\mathrm{N}_{1}$ at $\mathrm{O}_{2}$. Such dissociations offer further evidence that $N_{1}$ and $P_{2}$ can each be subdivided into distinctive central and occipital subcomponents.

For most VEP components, the summed amplitude over both visual fields during the divided attention condition did not differ significantly from the summed amplitude over attended and inattended stimuli in the focused conditions having the same schedule (Tables 2 and 4). Exceptions to this occurred for the $P_{2}$ wave at $\mathrm{O}_{2}$ and the $P_{3}$ wave at $\mathrm{C}_{\mathrm{z}}$, both of which had larger summed amplitudes during divided than during focused attention conditions at the slower rates (Table 4). There were no significant differences between VEPs to unattended stimuli and those evoked passively under any schedule.

Rate effects. It is clear from Table 2 that all VEP components decline in amplitude at the more rapid rate of stimulus delivery. This rate-dependent depression was significantly greater for responses measured at the vertex than at $\mathrm{O}_{2}$ for components $N_{1}, P_{1}-N_{1}$, and $N_{1}-P_{2}$, over all conditions of attention (each $\mathrm{p}<.01$ ). In the passive condition, however, only the $P_{2}$ and $N_{1}-P_{2}$ were significantly more refractory at the vertex than at $\mathrm{O}_{2}$ (both $\mathrm{p}<.01$ ). In no case did any component show greater rate- 
Table 4

Percentage Increments of VEP Components, Comparing Divided vs. Focused and Passive vs. Focused-Unattended Conditions

\begin{tabular}{|c|c|c|c|c|c|c|c|c|c|c|c|c|}
\hline & \multicolumn{6}{|c|}{$\mathrm{C}_{\mathrm{z}}$} & \multicolumn{6}{|c|}{$\mathrm{O}_{2}$} \\
\hline & $P_{1}$ & $\mathrm{~N}_{1}$ & $P_{2}$ & \multicolumn{2}{|c|}{$P_{1}-N_{1} N_{1}-P_{2}$} & \multirow{2}{*}{\multicolumn{2}{|c|}{$\frac{\mathrm{P}_{3} \quad \mathrm{P}_{1}}{\text { Replication }}$}} & \multirow{2}{*}{$\mathrm{N}_{1}$} & \multirow{2}{*}{$\mathrm{P}_{2}$} & \multicolumn{2}{|c|}{$P_{1}-N_{1} N_{1}-P_{2}$} & \multirow[t]{2}{*}{$\mathrm{P}_{3}$} \\
\hline & & & & & & & & & & & & \\
\hline $\begin{array}{l}\text { Divided vs. Mean of } \\
\text { Attend and Unattend }\end{array}$ & 7 & -14 & 2 & 2 & 4 & $41 *$ & 16 & -21 & $62 *$ & -2 & 27 & -2 \\
\hline \multirow[t]{2}{*}{ Unattend vs. Passive } & -23 & 36 & -7 & 17 & 10 & 44 & -23 & 19 & -17 & 0 & 0 & 16 \\
\hline & \multicolumn{12}{|c|}{ Slow Random } \\
\hline $\begin{array}{l}\text { Divided vs. Mean of } \\
\text { Attend and Unattend }\end{array}$ & 27 & 0 & 19 & 7 & 9 & $51 *$ & 38 & 20 & $58^{*}$ & 27 & 41 & 5 \\
\hline \multirow[t]{2}{*}{ Unattend vs. Passive } & 8 & 37 & -21 & 28 & 0 & -25 & -17 & 25 & -10 & 7 & 6 & 0 \\
\hline & \multicolumn{12}{|c|}{ Fast Random } \\
\hline $\begin{array}{l}\text { Divided vs. Mean of } \\
\text { Attend and Unattend }\end{array}$ & -40 & 11 & 2 & -5 & 6 & & 10 & 13 & 10 & 38 & 11 & \\
\hline Unattend vs. Passive & 0 & 0 & 4 & 0 & 3 & & -11 & 0 & -8 & -5 & -4 & \\
\hline
\end{tabular}

Note-Two-tailed t test on $\mu \mathrm{V}$ differences; significance levels $=* 01$.

dependent depression at the $\mathrm{O}_{2}$ site. Paralleling these amplitude changes, the latency of the $N_{1}$ wave at $\mathrm{C}_{\mathrm{z}}$ was significantly shorter (by $8 \mathrm{msec}$, Table 1) during the fast random schedule than at the slower rates, while the $\mathrm{N}_{1}$ latency at $\mathrm{O}_{2}$ was unchanged as a function of stimulus schedule $(p<.01$ for Electrode Site by Schedule interaction for $N_{1}$ ).

\section{Behavioral Measures}

The mean RT was significantly faster (by $11 \mathrm{msec}$ ) under the replication schedule than under the slow random schedule $(p<.025)$ and averaged $27 \mathrm{msec}$ faster $(p<.001)$ when the subjects responded to both visual fields (divided attention) rather than to a single field (focused attention) (Table 5). These RT effects were not paralleled by significant changes in the latency of the $\mathrm{P}_{3}$ component across conditions.

The detectability of target flashes in the fast random schedule was significantly lower $(p<.025)$ in the attend-both condition $\left(\mathrm{d}^{\prime}=1.26 \pm 0.15\right)$ than in the focused attention conditions $\left(\mathrm{d}^{\prime}=1.71 \pm 0.18\right.$ and $1.61 \pm 0.18$ for left- and right-field flashes, respectively). The decision criteria ( $\beta$ values) did not differ significantly between focused and divided attention conditions, averaging 2.91 for attend-left, 2.65 for attend-right, and 2.00 for attend-both conditions.

\section{DISCUSSION}

Shifts of attention between right and left spatial locations were found to produce strong and consistent modifications of specific components of the VEP under all experimental conditions. These attention-related changes observed using the random schedules fulfill the criteria for bona fide physiological signs of selective attention stated at the outset, namely: (1) specific VEP components showed reciprocal increases and decreases in amplitude to flashes in either field when attention was switched between them, (2) the order of stimulus delivery could not be anticipated by the subject, (3) lateral shifts of gaze and eye-movement artifacts were under control, and (4) behavioral evidence of selective processing was concurrently obtained. Moreover, the attention-related changes in the $P_{1}, N_{1}$, and $P_{2}$ components cannot be explained as consequences of selective motor responding, since they were present to the nontarget stimuli in the fast random condition, to which no motor responses were made. These results thus provide unequivocal evidence that selective attention to spatial location can be associated with distinct modifications of neurophysiological processing as reflected in the VEP.

The effects of attention on the $\mathrm{N}_{1}$ and $\mathrm{P}_{2}$ waves were not diminished in the slow random condition in comparison with the replication condition. This suggests that differential preparatory states of alertness or arousal (Näätänen, 1967; Karlin, 1970) did not contribute substantially to the experimental modifications of these components. The $\mathrm{P}_{1}$ wave, however, did show less enhancement during the slow random schedule than during the replication, at both $\mathrm{C}_{2}$ and $\mathrm{O}_{2}$ sites. This result tends to support

Table 5

Mean Reaction Times $( \pm \mathrm{SD})$ in the Different Conditions

Configuration

\begin{tabular}{llcc} 
& Replication & Slow Random & Mean \\
\hline Attend Left & $361 \pm 34$ & $376 \pm 36$ & 369 \\
Attend Right & $364 \pm 35$ & $366 \pm 33$ & 365 \\
Attend Both & $334 \pm 38$ & $346 \pm 40$ & 340 \\
Mean & 348 & 359 & \\
\hline
\end{tabular}


Näätänen's hypothesis that modulation of the subject's prior arousal, governed by his expectancy of stimulus delivery, can in some cases confound the effects of selective attention on EP amplitude. Näätänen's (1975) critique of the stimulus schedules used by Eason et al. (1969) receives further support from the present behavioral findings. Discriminative RTs were significantly faster with the replication than with the slow random schedule, suggesting that subjects can indeed predict the timing and order of stimuli with greater than chance accuracy when the two fields are governed by independent schedules. Thus, it is essential, in electrophysiological studies of selective attention, to prevent the possibility of differential stimulus expectancy and prior arousal by appropriate stimulus randomization.

In our replication of Eason et al.'s (1969) design, the predominant effects observed were on different VEP components than in the original study. The figures of Eason et al. depict a negative wave at $\mathrm{O}_{2}$, peaking at 160-180 msec (corresponding to our $\mathrm{N}_{1}$ ), which was at least twice as large, on the average, to attended-field flashes, but we observed no attentionrelated changes in this occipital component in the replication. We did, however, confirm Eason et al.'s observation that the subsequent positive peak at 200-220 msec $\left(P_{2}\right)$, and hence the $N_{1}-P_{2}$ measure, was substantially increased with the lateralized focusing of attention. The $P_{1}$ component (ca. 100$120 \mathrm{msec}$ ) was less evident in their tracings, but appeared to increase with attention in several subjects in accordance with our findings. The discrepancy between our results and those of Eason et al., regarding the occipital $N_{1}$ wave might possibly be attributed to higher motivation levels in their subjects (all were professional laboratory personnel whose RTs averaged some $100 \mathrm{msec}$ faster than these of the present inexperienced subjects) or, perhaps, to uncontrolled changes in their subject's visual fixation.

At the vertex recording site, on the other hand, the $\mathrm{N}_{1}$ component (ca. $155 \mathrm{msec}$ ) did show strong and consistent attention effects at all ISIs. Further distinctions between the occipital and central $N_{1}$ waves were observed in their latencies and relative refractory periods, with the vertex component being attenuated to a greater extent at the shorter ISIs. Lehtonen (1973) has similarly reported that the visually evoked $N_{1}-P_{2}$ components recorded centrally and occipitally can be dissociated from one another on the basis of differing latencies, refractory periods, and sensitivity to spatial structure in the stimulus. Lehtonen concluded that these "apparently similar late VEP deflections ... represent different neurophysiological phenomenon." He suggested that the occipital $N_{1}$ reflects "the function of the modality-specific cortical area" while the vertex $N_{1}$ is associated with "the function of a modality nonspecific area." This concept of parallel anterior and posterior foci for the late waves of the VEP might also help to explain discordant results of topographical mapping studies. Some investigators have reported a narrow, preoccipital focus for $\mathrm{N}_{1}$ and a parieto-occipital distribution for $\mathbf{P}_{2}$ (Simson et al., 1976), while others have found more anterior distributions for both of these waves (Allison, Goff, Williamson, \& VanGilder, in press; Goff, Matsumiya, Allison, \& Goff, 1969). It may be that differences in stimulus parameters or attentional requirements between studies bring one or the other of these parallel late waves into prominence.

It is perhaps not a coincidence that paying attention to one source or channel of auditory information (e.g., one ear) while ignoring a second source is also reflected most faithfully by changes in a vertex-centered " $\mathrm{N}_{1}$ " component of the auditory evoked potential (peaking at $90-120 \mathrm{msec}$ ). Like the vertex-recorded $N_{1}$ of the VEP, the auditory-evoked $N_{1}$ is preferentially enlarged to all attended-channel stimuli in relation to stimuli in an irrelevant channel (Hillyard et al., 1973; Hink, 1975; Schwent and Hillyard, 1975; Schwent et al., 1976a, 1976b, 1976c). Moreover, Hink et al. (in press) have found that the summed amplitude of the auditory $\mathrm{N}_{1}$ waves across both input channels (the two ears) remained relatively constant between conditions of focused and divided attention, as was shown here for the $N_{1}$ of the VEP. These cross-modality similarities make it tempting to speculate that the attention-sensitive portion of this vertex-negative wave between 90 and $160 \mathrm{msec}$ is a sign of nonspecific selective processing which operates with a limited overall capacity (at least in its physiological aspect). Hillyard et al., 1973, have suggested that the $N_{1}$ amplitude may be a general physiological sign of a "stimulus set" mode of selective attention which operates early in sensory processing to reject irrelevant stimuli "at the time of arrival, after analyzing as little information from them as possible" (Broadbent, 1970). Operating in parallel with this hypothesized general selection system, the attention-sensitive components of the occipital VEP might reflect modality-specific aspects of attention, a distinction analogous to that made by Lehtonen.

There are certain apparent discrepancies between the behavior of the auditory and visual "vertex potentials," however, which should be noted. In the auditory modality, the $\mathrm{N}_{1}$ wave was clearly differentiated between attended and irrelevant channels only when a fairly high information load was placed on the subject (mean ISI shorter than $0.5 \mathrm{sec}$ ) and moderate-to-low-intensity stimuli were used (Schwent et al., 1976a, 1976b). In the present study, however, we found clear evidence of attention effects on the vertex $N_{1}$ of the VEP (and other components 
as well) at much longer ISIs. This sensitivity of the VEP to manipulations of attention at slow rates of stimulation may reflect a difference between the two modalities in their underlying selection mechanisms. Alternatively, the requirement for rapid motor responses or the low intensity levels of the stimuli used may have augmented the attention effects. It should be emphasized, however, that the attention-related changes in sharp peaks such as $P_{1}$ and $N_{1}$ at the longer ISIs could not be caused by the addition of "motor potential" components (Gilden, Vaughan, \& Costa, 1966), since the RTs were too long and too poorly time-locked to the stimulus for this to occur. However, the later positive waves $\left(\mathrm{P}_{2}\right.$ and $\left.\mathrm{P}_{3}\right)$ could, in principle, be partially contaminated by motor potential components or by the termination of $\mathrm{CNV}$ waves which might have been present.

The late positive $\mathrm{P}_{3}$ (or $\mathrm{P}_{300}$ ) component was larger to the attended visual stimuli, which commanded a prompt motor response, in agreement with previous reports (Donchin \& Cohen, 1967; Eason et al., 1969; Harter \& Salmon, 1972). Parallel findings have been made using auditory and somatosensory cues, indicating that the $P_{3}$ wave is truly a modality nonspecific brain event (Ford, Roth, Dirks, \& Kopell, 1973; Smith, Donchin, Cohen, \& Starr, 1970; Velasco, Velasco, Machado, \& Olvera, 1973). Moreover, attention-related enhancement of $P_{3}$ has been dissociated from changes in the earlier evoked $\mathbf{N}_{1}$ and $\mathbf{P}_{2}$ components, in both auditory and visual modalities (e.g., Courchesne et al., 1975; Ford et al., 1973; Harter \& Salmon, 1972; Hillyard et al., 1973; Smith et al., 1970; present study). Hillyard et al. (1973) have suggested that the $P_{3}$ wave reflects a different mode of attention from the earlier $N_{1}$ component, perhaps akin to Broadbent's (1971) "response set" selection. The present study revealed yet another distinction between the $N_{1}$ and $P_{3}$ waves during attention tasks. While the total $N_{1}$ amplitude output remained constant when responses were directed to both channels (divided attention), the total $P_{3}$ output at the vertex was augmented by this demand for an increased rate of responding. This suggests that the capacity for response selection or decision making that is indexed by $\mathrm{P}_{3}$ was not fully utilized in the focused attention condition.

In the recent behavioral literature on visual attention, divergent views have been expressed about the ability of human observers to attend selectively to a specific locus in space. The question being debated is whether or not focusing attention on one source results in preferential processing of those stimuli in relation to those from unattended sources. Posner, Nissen, and Ogden (in press) reported that advance cueing of the position of a flash facilitated the simple RT to correctly cued flashes and retarded the RT to falsely cued flashes. They interpreted this effect as "a change in an input pathway and/or attentional mechanisms as a function of expectancy." On the other hand, Shiffrin, McKay, and Shaffer (1976) reported that the detectability of flashes is not improved when their spatial location is known in advance and that many spatial loci (up to 49) can be attended at once "without essential loss of processing quality." This conclusion was based on their finding that flash detectability at central loci remained constant whether subjects focused attention on those positions or divided their attention between the central position(s) and a peripheral set of positions. In the present fast random condition, which involved a difficult brightness discrimination, however, subjects could not attend to two spatial locations at once without a decrement in target detectability. Moreover, the VEP results indicate that information from attended and unattended visual loci was, in fact, being processed differentially by at least 100 msec poststimulus, and perhaps earlier. This behavioral and electrophysiological evidence converges on the conclusion that the human visual system does have a mechanism for selectively processing information from attended spatial positions.

\section{REFERENCES}

allison, T., Goff, W. R., Williamson, P. D., \& Van Gilder, J. C. On the neuronal origin of early components of the human somatosensory evoked potential. In J.Desmedt (Ed.), Proceedings of Brussels Congress on Cerebral Evoked Potentials in Man. London: Oxford University Press, in press.

Broadbent, D. E. Stimulus set and response set: Two kinds of selective attention. In D. I. Mostofsky (Ed.), Attention: Contemporary theory and analysis. New York: Appleton-CenturyCrofts, 1970.

Broadbent, D. E. Decision and stress. New York: Academic Press, 1971.

Chapman, R. M. Evoked potentials of the brain related to thinking. In F. J. McGuigan (Ed.), The psychophysiology of thinking. New York: Academic Press, 1973.

Courchesne, E., Hillyard, S. A., \& Galambos, R. Stimulus novelty, task relevance and the visual evoked potential in man. Electroencephalography and Clinical Neurophysiology, 1975, 39. 131-143.

Donchin, E., \& Cohren, L. Averaged evoked potentials and intramodality selective attention. Electroencephalography and Clinical Neurophysiology, 1967, 22, 537-546.

Eason, R., Harter, M., \& White, C. Effects of attention and arousal on visually evoked cortical potentials and reaction time in man. Physiology and Behavior, 1969, 4, 283-289.

Ford, J. M., Roth, W. T., Dirks, S. J., \& Kopeli, D. S. Evoked potential correlates of signal recognition between and within modalities. Science, 1973, 181, 465-466.

Gilden, L., Vaughan, H. G., \& Costa, L. D. Summated human EEG potentials with voluntary movement. Electroencephalography and Clinical Neurophysiology, 1966, 20, 433-438.

Goff, W. R., Matsumiya, Y., Allison, T., \& Goff, G. D. Cross-modality comparisons of average evoked potentials. In $\mathrm{E}$. Donchin \& D. B. Lindsley (Eds.), Average evoked potentialsmethods, results and evaluations. Washington, D.C: NASA, 1969. Pp. 95-141.

HARTER, M. R., \& SALmon, L. E. Intra-modality selective attention and evoked cortical potentials to randomly presented pat- 
terns. Electroencephalography and Clinical Neurophysiology, $1972,32,605-613$.

HARTLEY, L. R. The effect of stimulus relevance on the cortical evoked potentials. Quarterly Journal of Experimental Psychology, 1970, 22, 531.546.

Hilly ard, S. A., Hink, R. F., Schwent, V. L., \& Picton, T. W. Electrical signs of selective attention in the human brain. Science, 1973, 182, 177-180.

Hillyard, S. A., \& Picton, T. W. Event-related brain potentials and selective information processing in man. In J. Desmedt (Ed.), Proceedings of Brussels Congress on Cerebral Evoked Potentials in Man. London: Oxford University Press, in press.

Hinx, R. F. Selective attention and the human evoked ptoential to phonetic stimuli. Doctoral dissertation, University of California at San Diego, 1975.

Hink, R. F., \& Hillyard, S. A. Auditory evoked potentials during selective listening to dichotic speech messages. Perception \& Psychophysics, 1976, 20, 236-242.

Hink, R., Van Voorhis, S., Hillyard, S., \& Smith, T. Divided attention and the human auditory evoked potential. Neuropsychologia, in press.

KARLIN, L. Cognition, preparation and sensory-evoked potentials. Psychological Bulletin, 1970, 73, 122-136.

LeEtonen, J. B. Functional differentiation between late components of visual evoked potentials recorded at occiput and vertex. Electroencephalography and Clinical Neurophysiology, 1973, 35, 75-82.

NÄ̈ränen, R. Selective attention and evoked potentials. Annals of the Finnish Academy of Science, 1967, 151, 1-226.

NÄ̈ÄnEN, R. Selective attention and evoked potentials in humans-a critical review. Biological Psychology, 1975, 2, 237-307.

Posner, M. I., Nissen, M. J., \& OgDen, W. C. Attended and unattended processing modes: The role of set for spatial location. In M. L. Pick (Ed.), Modes of perceiving and processing information. Hillsdale, N.J: Erlbaum, in press.

Ritter, W., Simson, R., \& Vaughan, H. G., JR. Association cortex potentials and reaction time in auditory discrimination. Electroencephalography and Clinical Neurophysiology, 1972, 33, 547-555.

Rohrbaugh, J. W., Donchin, E., \& Eriksen, C. W. Decision making and the $\mathbf{P} \mathbf{3 0 0}$ component of the cortical evoked response. Perception \& Psychophysics, 1974, 15, 368-374.

Ruchkin, D. S., \& Sutron, S. Visual evoked and emitted potentials and stimulus significance. Bulletin of the Psychonomic Society, 1973, 2, 144-146.

Schwent, V., \& Hillyaro, S. A. Auditory evoked potentials and multi-channel selective attention. Electroencephalography and Clinical Neurophysiology, 1975, 38, 131-138.

Schwent, V. L., Hillyard, S. A., \& Galambos, R. Selective attention and the auditory vertex potential. I: Effects of stimulus delivery rate. Electroencephalography and Clinical Neurophysiology, 1976, 40, 604-614. (a)

Schwent, V. L., Hillyard, S. A., \& Galambos, R. Selective attention and the auditory vertex potential. II: Effects of signal intensity and masking noise. Electroencephalography and Clinical Neurophysiology, 1976, 40, 615-622. (b)

Schwent, V. L., SNyder, E., \& Hillyard, S. A. Auditory evoked potentials during multichannel selective listening: Role of pitch and localization cues. Journal of Experimental Psychology, 1976, 2, 313-325. (c)

Shiffrin, R. M., McKay, D. P., \& Shaffer, W. O. Attending to forty-nine spatial positions at once. Journal of Experimental Psychology, 1976, 2, 14-22.

Simson, R., Vaughan, H. G., \& Ritter, W. The scalp topography of potentials associated with missing visual or auditory stimuli. Electroencepholography and Clinical Neurophysiology, $1976,40,33-42$.

Smith, D. B. D., Donchin, E., Cohen, L., \& Starr, A. Auditory average evoked potentials in man during binaural listening.
Electroencephalography and Clinical Neurophysiology, 1970, 28 , 146-152.

Soutres, N., Donchin, E., Squires, K., \& Grossberg, S. Redundant information in auditory and visual modalities: Inferring decision-related processes from the $\mathrm{P} 300$ component. Journal of Experimental Psychology, in press.

Swets, J. A., \& Kristofferson, A. B. Attention. Annual Review of Psychology, 1970, 21, 339-366.

Trevarthan, C. B., \& TuRsKy, B. Recording horizontal rotations of head and eyes in spontaneous shifts in gaze. Behavior $\boldsymbol{R e}$ search Methods \& Instrumentation, 1969, 1, 291-293.

Velasco, M., Velasco, F., Machado, J., \& Olvera, A. Effects of novelty, habituation, attention and distraction on the amplitude of the various components of the somatic evoked responses. International Journal of Neurosciences, 1973, 5, 101-111.

\section{NoTES}

1. In some subjects, a small amount of dc drift persisted in the EOG recording, but these steady (nearly linear) and unidirectional dc shifts could easily be distinguished from the more rapid deflections resulting from saccadic eye movements. Moreover, the direction of the dc drift throughout a block was independent of the field to which the subject directed his attention (as assessed by a chi-square test over all runs). Thus, there was no overall tendency for the subject's eyes to "wander" towards the direction of the attended flashes.

2. In a detection experiment of this type, where each stimulus is not associated with a clearly defined response interval, a hit can be defined as a response which falls within a specified posttarget latency window. In these circumstances, the theoretical values of $P($ Hit) and $P(F . A$.$) for a random responder are strictly$ dependent upon the relative durations of the appropriate response windows, not the probabilities of target and nontarget stimulus presentation. It is, therefore, necessary to define the experimentally obtained $\mathrm{P}(\mathrm{Hit})$ and $\mathrm{P}(\mathrm{F} . \mathrm{A}$.) in terms of the appropriate response window durations

In this experiment, we defined the response interval for a hit as an 800 - $\mathrm{msec}$ window beginning $200 \mathrm{msec}$ posttarget, since pilot data had indicated that the vast majority of correct responses would fall within this latency range. The first response within this range terminated the window, precluding the possibility of recording more than one hit per target presentation. The ratio of the number of responses recorded within the hit response windows to the number of hit response windows defined $\mathrm{P}(\mathrm{Hit})$. The total duration of the trial block minus the summed duration of the hit response windows was then divided by 800 msec to obtain the number of false-alarm windows. The $P(F . A$.) was defined as the ratio of the number of responses outside the hit response windows to the number of false alarm intervals. This procedure has the advantage of generating the appropriate ROC curve $\left[P(\right.$ Hit $)=P(F . A$. $)$ and $\left.\mathrm{d}^{\prime}=0\right]$ for a random responder receiving no sensory information. For a further discussion of signal detection with undefined observation intervals, see Swets and Kristofferson (1970).

3. These percent values were obtained by subtracting the amplitudes of the unattended field response from those of the attended field, dividing by the former, and then multiplying by 100 . The $t$ tests of dependent means $(d f=11)$ reported in Tables 3 and 4 were calculated form the $\mu \mathrm{V}$ difference scores (one for each subject) between responses to attended vs. unattended stimuli.

(Received for publication February 28, 1977; accepted April 19, 1977.) 